\title{
Base-Isolated Buildings: Towards Performance-Based Design
}

\author{
James P. Talbot \\ Department of Engineering, University of Cambridge, UK \\ ipt1000@cam.ac.uk
}

\begin{abstract}
Base-isolated buildings, founded on steel springs or elastomeric bearings, have been employed since the 1960s in locations susceptible to groundborne vibration. Examples exist across a wide range of buildings, from residential to commercial, and include specialist buildings such as concert halls and hospitals. In all cases, the objective is to reduce internal levels of perceptible vibration and reradiated noise, with the most common sources of concern being nearby surface or underground railways. Despite the extensive use of base isolation, there is a significant lack of guidance on all aspects of design, from the selection of bearing type and their location within a building, to questions such as how performance should be evaluated, and the most fundamental question of all: is isolation necessary? This paper reviews current practice in base-isolation design, and highlights some of the challenges and future research efforts in moving towards a performance-based design approach for controlling groundborne vibration.
\end{abstract}

Keywords: dynamics, buildings, structures \& design

\section{Notations List}

$\mathbf{H}_{b}^{11} \quad$ frequency-response function matrix of the building

$\mathbf{H}_{f}^{11} \quad$ frequency-response function matrix of the foundation

I identity matrix

$\mathbf{u}_{b f} \quad$ vector of displacements on the building-foundation interface in the presence of the building

$\mathbf{u}_{b f 0} \quad$ equivalent to $\mathbf{u}_{b f}$ in the absence of the building, prior to construction 


\section{Introduction}

In general, modern structures are increasingly susceptible to vibration, as designs become more efficient. Although strength is assured via standard design procedures, it is common for insufficient structural mass, stiffness and/or damping to lead to unacceptable levels of dynamic response (see Table 1). This increased susceptibility to vibration has developed at the same time as pressure has grown to build on sites affected by groundborne vibration, primarily due to the presence of underground railways and urban tram networks but also as a result of increased road traffic. As a result, groundborne vibration is a growing concern for practicing engineers, who also face increasingly stringent noise and vibration limits as part of wider design serviceability requirements.

Table 1. Traditional vs modern building design with regard to vibration sensitivity

\begin{tabular}{|l|l|}
\hline \multicolumn{1}{|c|}{ Traditional } & \multicolumn{1}{c|}{ Modern } \\
\hline Massive and stiff (masonry, bulk concrete) & $\begin{array}{l}\text { Light-weight and flexible (pre-stressed concrete, } \\
\text { steel frames, strength-optimised design) }\end{array}$ \\
\hline Short (high frequency) spans (by necessity) & $\begin{array}{l}\text { Long (low frequency) spans (by design, e.g. open- } \\
\text { plan offices) }\end{array}$ \\
\hline $\begin{array}{l}\text { Heavily damped (many joints / frictional } \\
\text { interfaces) }\end{array}$ & $\begin{array}{l}\text { Lightly damped (fewer joints, reduced cracking, } \\
\text { glazed facades, open-plan 'minimalist' interiors) }\end{array}$ \\
\hline
\end{tabular}

Typical building vibration levels due to road and railway traffic lie in the range from $0.1 \mathrm{~mm} / \mathrm{s}$ to 1.0 $\mathrm{mm} / \mathrm{s}$, which is significantly below the level at which even light damage, such as the cracking of plaster, may be expected. Nevertheless, the disturbance caused to building occupants, and the disruption caused in specialist buildings, such as hospitals and research facilities, can have significant social and economic consequences. Disturbance may be caused in two ways: by unacceptable levels of structural vibration; and/or by re-radiated noise (sometimes known as structure-borne or groundborne noise), which radiates in the audible frequency range from vibrating elements of the building. In the case of groundborne vibration due to railways, both structural vibration and reradiated noise tend to be most noticeable in the frequency range from approximately $25 \mathrm{~Hz}$ to $250 \mathrm{~Hz}$, with the latter manifesting as a low-frequency 'rumble'.

\subsection{Base Isolation}

Base isolation of buildings is well established as one of the most effective techniques for limiting the disturbance caused by groundborne vibration. Since the first examples were built in the 1960s (Waller, 1969), base-isolated buildings have become commonplace in our major cities. Examples exist across a wide range of buildings, from offices and apartments (Boxoen et al., 2010; Moss, 1982) to specialist buildings such as concert halls (Commins et al., 1990), cinemas (Henson and Charles, 2000), hospitals (Grootenhuis, 1990) and broadcasting studios (Henson, 2009). In all cases, the objective is to reduce vibration transmission into the building by incorporating isolation bearings within the primary structure. For modern buildings, this usually involves inserting either elastomeric bearings or steel helical springs between the base of the primary structure and the foundation.

Despite the extensive use of base isolation, there is a significant lack of either national or international guidance on all aspects of design. The only standard of direct relevance to base isolation is the 
British Standard BS 6177 (1982), which was formally withdrawn in 2013. This deals specifically with elastomeric bearings and is concerned principally with safety and practical aspects, such as bearing construction, stability, stiffness testing, etc. A useful appendix lists factors to be considered in the overall isolation design but no theoretical background or quantitative guidance is provided concerning the effectiveness of bearings as vibration isolators. Other publications, such as the American FTA guidelines (Hanson et al., 2006), provide more general guidance on the measurement and assessment of groundborne vibration but none provide specific guidance on the design and evaluation of base-isolation systems. Fundamental questions remain, ranging from the selection of bearing type and their location within a building, to questions such as how performance should be evaluated, and the most fundamental question of all: is isolation necessary?

\subsection{Fundamental Principles}

In broad terms, the fundamental principles underlying base-isolation against groundborne vibration are similar to those underlying base-isolation against earthquakes: both involve a dynamic decoupling of the building from its foundation (Naeim and Kelly, 1999). However, both the governing theory and the practical implementation differ in detail due to the nature of the ground motion, which, in the case of groundborne vibration, is several orders of magnitude lower in amplitude, and with a broader and higher frequency content.

The principles of base isolation are often introduced by reference to the single-degree-of-freedom (SDOF) model, which represents the building as a rigid mass supported on some form of springdamper element to represent the isolation bearing (see Figure 1). The performance of the base isolation is described simply by the ratio of the displacement amplitude of the mass to that of the imposed ground motion at the base. The precise expression describing the frequency dependence of this ratio depends on the nature of the damping model used but the essential features are the same in all cases: (1) the bearings act to amplify any low-frequency vibration, and this is greatest at the (natural) isolation frequency; (2) the bearings are only effective for frequencies greater than $\sqrt{2}$ times the isolation frequency, above which the isolation improves with frequency; and (3) damping acts to limit the resonance amplitude but reduces the isolation performance.

These features of the SDOF model may suggest some guiding design principles but the model is far too simplistic for making any useful predictions of isolation performance. Indeed, the model may be regarded as being so simplistic as to be misleading. There are a number of key shortcomings.

- Whilst a SDOF representation of the building may be acceptable in seismic design, where the response is often dominated by a single, low-frequency global vibration mode, this is clearly an oversimplification when dealing with the response to groundborne vibration. Within the frequency range of groundborne vibration, the modal density in the building is relatively high and the response comprises many higher vibration modes, all of which tend to reduce the effectiveness of the isolation relative to the SDOF prediction. 


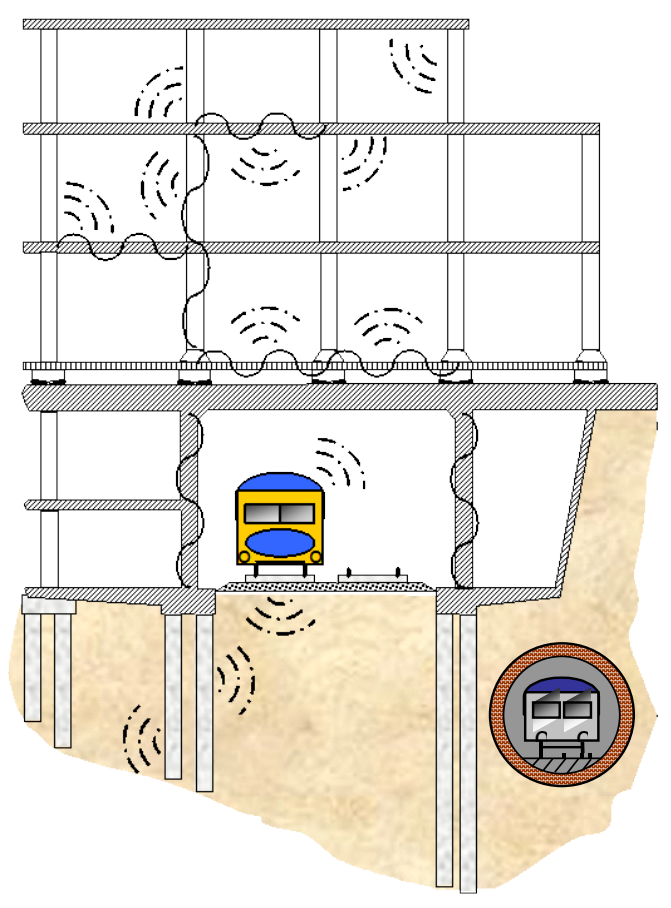

(a)

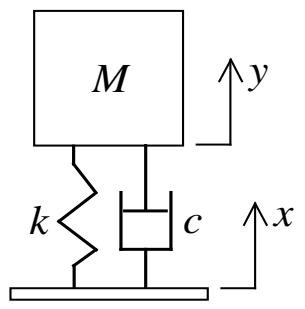

(b)

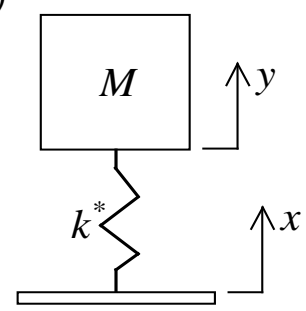

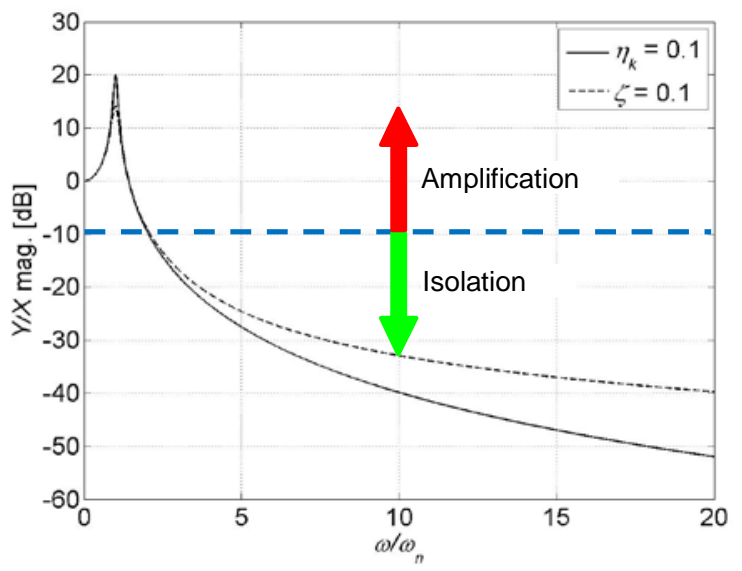

Figure 1. The SDOF model of a base-isolated building, where the rigid mass $M$ represents the building and the linear spring $k$ represents the isolation bearing. Damping may be accounted for by (a) a viscous dashpot or (b) a complex (hysteretic) spring stiffness.

- The focus on a SDOF suggests that only one direction of motion is significant, and potentially leads to the effects of multiple vibration inputs being overlooked. This is less of a concern in seismic design because the dominant input motion often acts horizontally and, due to the wavelengths involved, uniformly across a foundation.

- The absence of any representation of the foundation and surrounding ground ignores the effects of soil-structure interaction. This has been known for some time as being significant in the seismic response of buildings but its significance with regard to groundborne vibration has only begun to be recognised relatively recently.

At least some of these shortcomings are generally recognised, and the SDOF model is rarely used as the sole basis for predicting isolation performance. More comprehensive models are required in practice, as discussed below.

\section{Current Design Practice}

There are a number of generic, practical aspects associated with the specification and design of base-isolation systems that must be considered in any project. Examples include: settlement of the building on its bearings, either during construction or subsequently through creep in the bearings; fire 
proofing of the bearings, and designing failsafe measures for the unlikely event of a collapsed bearing. Care must also be taken not to 'bridge' the isolation by, for example, staircases, building services, construction debris or acoustic coupling. Such aspects are now generally understood and incorporated into established design practice; many are covered in BS 6177 and have been reported in a number of design case-studies (e.g. Henson and Charles, 2000).

This paper is concerned with designing a system to achieve a specified isolation performance, and the common challenges that this involves. There are two fundamental stages: developing the specification, in terms of serviceability limits on the level of disturbance within the particular building; and designing a system to meet these, given the particular nature of the vibration at the site in question.

\subsection{Serviceability Limits}

In certain buildings, such as specialist manufacturing or research facilities, design serviceability limits on structural vibration are dictated by the presence of sensitive equipment (Gordon, 1991). These limits, which usually lie below the threshold of human perception, are relatively straightforward to define as there are no human factors involved. Once the vibration becomes perceptible, the level that may be considered acceptable is dependent upon many factors, such as the duration and nature of the vibration, the type of building and the activities of its occupants (Griffin, 1990).

Several standards aim to provide guidance on acceptable levels of perceptible vibration in buildings, such as the commonly encountered British and German standards BS 6472-1 (2008) and DIN 4150-2 (1999), and the international standard ISO 2631-2 (2003). One of these standards typically forms the basis of serviceability limits on vibration for most base-isolated building projects. However, in most cases, the overriding concern is not perceptible vibration but rather re-radiated noise; simply because this usually reaches unacceptable levels before the vibration itself. This is unfortunate because there is even less agreement on re-radiated noise limits than there is on those governing vibration. There are no internationally agreed limits for re-radiated noise, and recommended national limits vary significantly (Elias and Villot, 2012). Commonly encountered limits are those published by the American FTA (Hanson et al., 2006), whilst some of the most stringent to date are those adopted in the UK for London Underground (Transport for London, 2012).

A comprehensive commentary on serviceability limits, for either vibration or re-radiated noise, is beyond the scope of this paper: full details, including the particular metrics used, are available in the above references. The important point to emphasise here is the level of uncertainty faced by the practicing engineer, with significant differences between adopted limits and significant uncertainty over their robustness, human nature being what it is. Even the most robust criteria are based on human dose-response studies, which only indicate the average level of community annoyance. It is therefore important that, whatever limits are adopted for a particular project, this uncertainty is recognised formally from the outset and borne in mind throughout the design process. 
One final comment, applicable to both noise and vibration limits, concerns the common use of the logarithmic, decibel scale. This is such that a difference of $3 \mathrm{~dB}$, in either noise or vibration levels, is equivalent to a factor of two in energy, whilst $10 \mathrm{~dB}$ is equivalent to an order of magnitude. Although the human perception of such differences can be complex, this relationship between decibel level and energy is worth remembering, for example, when assessing model prediction accuracy or the effectiveness of vibration mitigation techniques.

Whatever the adopted limits, in practice, the decision on whether or not to base-isolate a building is usually based on a combination of prior experience, site vibration measurements, some form of modelling to predict noise and vibration levels in the completed building, and the perceived risk of disturbance.

\subsection{Site Measurements}

Site measurements are invaluable in design because they may be used, in combination with an appropriate building model, to reduce the significant uncertainties inherent in modelling a particular vibration source. For a particular site, it is usual to characterise the vibration in terms of its magnitude and frequency content, as measured on the free surface of the ground at salient locations within the footprint of the proposed building. Ideally, measurements should be made following the demolition and removal of any redundant structures but prior to the new construction, since these can both modify the ground vibration field.

General guidance is readily available on the practical aspects of vibration measurement (Association of Noise Consultants, 2012) but there are some particular aspects of relevance to base-isolated buildings that are often overlooked. The first point worth stressing is the repeatability of any measurements. Usually, the source is a nearby road or railway, with significant variability in magnitude, and possibly frequency content, between vehicle passages. It is therefore essential that the vibration is characterised in a statistical sense, with a mean source spectrum and some indication of the variance. The signal processing required for this analysis is itself a potential source of error and must be undertaken carefully (Newland, 1993).

Perhaps due to a combination of the legacy of the SDOF model and the practicalities of making multiple tri-axial measurements, it remains common practice to measure only vertical vibration of the ground. However, in general, the structural elements at the base of a building - the footings or the pile caps - exhibit a combination of vertical, horizontal and rotational vibration. Theoretical evidence suggests that connected building columns can amplify apparently insignificant levels in these other directions, through the excitation of flexural vibration, which subsequently couples to vibration of floors and walls located higher up the building (Talbot and Hunt, 2003a). Further research is required in this area but, nevertheless, it is good practice to measure and attempt some form of assessment of the significance of these other directions. 
A more difficult aspect to assess is the degree of correlation in vibration levels across a site. This can vary from being well correlated, particularly at low frequencies (long wavelengths), to substantially uncorrelated. Again, further research is required but it is clear from theoretical models that the predicted building response can vary significantly depending on whether or not correlated inputs are assumed (Hunt, 1996).

\subsection{Design Evaluation}

Any design requires evaluation in terms of its ability to meet the specified serviceability limits. This usually requires some form of absolute prediction of the isolation performance, that is, predictions of vibration and/or re-radiated noise levels in the completed building. In principle, such predictions may be attempted using either empirical models, based on a database of measurements, or theoretical models based on physical laws. The former can rapidly provide valuable reference data and some indication of the levels of disturbance that may be expected (Hanson et al., 2006). However, it is important to highlight the high degree of uncertainty associated with such predictions, which treat each part of the vibration transmission path independently. In particular, the use of measured 'ground-to-building' transfer functions, which aim to predict how vibration propagates from the ground into a building, do not represent the coupled nature of the soil-structure interaction between a building and its foundation. Furthermore, all buildings are to some extent unique, and it is unlikely that any historical database is sufficiently comprehensive to cover precisely the particular combination of source, transmission path and building in question. Empirical models are therefore not ideal for assisting with the design of a particular base-isolated building; they are best reserved for high-level 'scoping' assessments, such as those undertaken for more general environmental impact studies.

The alternative, theoretical approach has the advantage that models may be tailored to the particular project, at least in principle, including as much physical detail as necessary from the vibration source to the receiving building (Lopez et al., 2014; Fiala et al., 2007). For practicing engineers, the natural approach is to use a commercial finite-element code, since these are readily available and often already employed in the structural (static) design. However, although modern numerical methods now enable comprehensive 'source-to-receiver' models, these remain computationally expensive and are research-oriented rather than design-oriented. They too suffer from significant levels of uncertainty.

In discussing their extensive numerical model for predicting building vibration and re-radiated noise due to surface railways, Fiala et al. (2007) acknowledge that the practical application of such a model is limited by the availability and uncertainty of data on material properties, structural details, soil inhomogeneity, etc. Gupta et al. (2009a) present a parametric study on the determining factors for vibration from underground railways, as predicted by a similar numerical model. Amongst their conclusions they report variations of between $4 \mathrm{~dB}$ and $6 \mathrm{~dB}$ in the maximum RMS surface vibration levels due to a $50 \%$ variation in the soil shear modulus; similar variations are reported due to a $50 \%$ variation in the soil damping ratio. Such variations in these important model input parameters are 
commonly measured in practice. A related numerical investigation by Jones et al. (2012) considered six commonly disregarded aspects of the underground railway environment and their effects on vibration prediction: a second (twin) tunnel, piled foundations, track with discontinuous slabs, soil inhomogeneity, inclined soil layers, and irregular contact at the tunnel-soil interface. The results suggest that each of these simplifying assumptions can result in vibration predictions that vary from the simplified cases by at least $5 \mathrm{~dB}$ and potentially up to $20 \mathrm{~dB}$.

These theoretical findings are supported by measurements. Gupta et al. (2009b) report on the validation of an extensive numerical model using a comprehensive set of vibration measurements made on London Underground, covering the vehicle, tunnel and free field, both at the surface and at depth. They conclude that it is difficult to achieve a source-to-receiver prediction accuracy of better than $10 \mathrm{~dB}$.

In the light of this significant modelling uncertainty - the level of which is comparable to vibration reductions achievable with typical mitigation techniques, including base isolation - the value of deterministic modelling as the sole basis of design evaluation is clearly limited. At best, current models must be regarded as suitable for guiding design only, by predicting the relative performance of different design options, rather than producing reliable predictions of absolute performance. Guidance can indeed be obtained by modelling alone, and there are examples of case studies where this has been invaluable (e.g. Talbot and Hunt, 2003b). However, it is clear that, wherever possible, site measurements should be used to support modelling and reduce uncertainty, in particular, to characterise the vibration source and thereby avoid the need to model this, and the associated transmission path, explicitly. One example application of such a hybrid approach, based on structural models in combination with in-situ source measurements, is reported by Francois et al. (2014).

\section{Towards a Performance-Based Design Approach}

The lack of guidance on all aspects of base-isolated building design is a matter of significant concern for practicing engineers. There is a real need for an efficient, evidence-based design approach, based on robust engineering science that acknowledges the levels of uncertainty and specific practical constraints encountered in practice. Again, parallels may be drawn in the field of seismic engineering, within which, over the last decade or so, significant efforts have been made to develop new design procedures and guidelines that lead to structures of predictable seismic performance (Ghobarah, 2001). This is being achieved by adopting a performance-based design approach, in which structural design criteria are expressed in terms of achieving specific performance objectives (Becker and Foliente, 2005). In the context of base-isolated buildings, the main steps in such an approach may be summarised as follows:

- identify and formulate the relevant User Requirements based on building occupancy and usage; 
- transform the User Requirements into Performance Objectives, that is, noise and vibration serviceability limits;

- use reliable design and evaluation methods to assess whether proposed solutions meet the specified limits at a satisfactory level.

There are several challenges to be addressed before the above steps may be formally defined within new design guidance. As indicated in Section 2, there remains significant uncertainty over the definition of performance objectives, particularly with regard to serviceability limits covering human disturbance. Further work is clearly required in this area, to consolidate previous research and practical experience, with a view to establishing universal agreement on limits for both perceptible vibration and re-radiated noise in buildings. Such limits are required in terms of the probability of disturbance, to formally quantify the inherent uncertainties associated with human response.

In the area of design evaluation, a significant amount of further research is required to develop generic methods based on numerical models that are versatile, robust and efficient. Some research priorities are discussed below.

\subsection{Soil-Structure Interaction}

An outline deterministic approach to modelling for the prediction of base-isolation performance, which is independent of the particular methods used, is presented by Talbot (2007). Given the predominantly linear (low strain) and steady-state nature of groundborne vibration response, the approach is formulated in the frequency domain. This is generally more efficient than working in the time domain and may be readily extended to include a formal treatment of response statistics. A key equation allows the final displacements at locations on the building-foundation interface, in the presence of the building, $\mathbf{u}_{b f}$, to be calculated from those prior to its construction, $\mathbf{u}_{b f 0}$ :

$$
\mathbf{u}_{b f}=\left[\mathbf{I}+\mathbf{H}_{f}^{11}\left[\mathbf{H}_{b}^{11}\right]^{-1}\right]^{-1} \mathbf{u}_{b f 0}
$$

where $\mathbf{H}_{f}^{11}$ and $\mathbf{H}_{b}^{11}$ are the frequency-response function matrices of the foundation and building that relate displacements and forces on the building-foundation interface, $\mathbf{I}$ being the identity matrix.

The important point to note here is that $\mathbf{u}_{b f} \neq \mathbf{u}_{b f 0}$ : the construction of a building, in general, modifies the ground vibration field. This is the effect of soil-structure interaction (SSI) highlighted earlier. It has been known for some time as being significant in the seismic response of buildings but its significance with regard to groundborne vibration has only begun to be recognised relatively recently with the development of more comprehensive models (Talbot, 2007; Hussein et al., 2013; Coulier et al., 2014). In the design of base-isolated buildings, it is common to evaluate the absolute performance of the 
proposed isolation by taking vibration levels measured at the proposed site, prior to any construction work, and applying these to the base of a building model in an attempt to predict the final vibration levels in the completed building. This is often done without any reference to the ground or building foundation - a fundamentally flawed approach because it fails to account for some important effects of SSI. There are two primary effects: (1) the soil provides significant radiation damping to the building structure, through the geometric spreading of vibration wavefronts; and (2) the coupling of a structure to the soil acts to modify the free-field vibration. Importantly, both effects are such that ignoring them tends to over-predict vibration levels in the completed building, and by a margin - up to approximately $10 \mathrm{~dB}$, according to current models (Coulier et al., 2014; Talbot et al., 2014) - that in many cases could render isolation unnecessary. There is little doubt that the widespread practice of ignoring SSI is likely to produce conservative but potentially inefficient designs.

The incorporation of SSI into formalised design evaluation methods is therefore a key priority. Further consideration must be given not just to the interaction between a building and its foundation, as expressed by Equation 1, but also to the interaction between a foundation and the free-field.

It is worth noting that the formulation encapsulated in Equation 1, whilst accounting fully for the coupling (SSI) between the building and its foundation, neglects that between the building and the vibration source. The source is assumed to generate an incident wave field that interacts with the building and its foundation but without this interaction influencing the mechanisms of vibration generation at the source. This assumption is supported by recent theoretical evidence that suggests building-source coupling is indeed weak, and may be ignored provided the distance between the two is sufficiently large (Coulier et al., 2014).

\subsection{Non-structural Cladding and Partitions}

Typical building models naturally focus on the primary structure - the steel or concrete portal frame and its floors - since this is the focus of the static design. It is rare that consideration is given to nonstructural elements, such as the exterior cladding and internal partitions. Whilst some account may be taken of non-structural mass (for example, by increasing the density of elements representing floor slabs), the associated stiffness and damping is usually ignored.

Measurements made for assessing the low-frequency footfall response of floors suggest that the additional stiffness due to both exterior cladding and internal partitions may indeed be significant. Devin et al. (2015) measured a $30 \%$ increase in the fundamental natural frequencies of two floor slabs, together with associated changes in modal properties, as a result of the addition of such elements to a concrete-framed building. Similar measurements have indicated that, at the small strain levels concerned, friction acting along the joint with a façade can apply significant constraint to the edges of a floor slab (Willford and Young, 2006; Smith et al., 2009). 
Although these effects are significant when attempting to predict footfall induced vibration, the modal density in the building at groundborne frequencies is much higher, and the overall effects of changes to a few low-frequency modes are currently uncertain. The significance of non-structural elements within the higher frequency range of groundborne vibration therefore remains to be established.

\subsection{Quantifying Uncertainty and the Application of Energy-Based Methods}

The application of deterministic modelling in the design of base-isolated buildings is likely to remain limited to making relative predictions of isolation performance, to guide design development and optimise chosen solutions. To establish a reliable approach to absolute performance prediction, methods must be developed that express performance in probabilistic terms, such as the expected mean vibration levels and their variance. Only then can predictions be compared sensibly against vibration serviceability limits to provide an overall probability of disturbance.

Further research is required to establish which modelling parameters are most significant in the prediction of building vibration, and to quantify the inherent uncertainties. As part of this work, new performance metrics are being used based on vibration energy rather than vibration amplitude. Insertion gain (IG) is typically used to describe the performance of base-isolated buildings, by comparing building vibration amplitudes with and without isolation bearings in position. However, being based on amplitude, IG varies with direction and position within a building, and it is unsuitable for providing an overall measure of performance (Talbot and Hunt, 2000). Power-flow insertion gain (PFIG), based on the mean vibrational power flowing into a building, is a more useful measure because it provides a single frequency-dependent metric that also accounts for multidirectional vibration at multiple inputs and is insensitive to the spatial distribution of vibration levels (Talbot and Hunt, 2003a). It is particularly effective for assessing model sensitivity, as illustrated in recent work on the significance of building-source coupling (Coulier et al., 2014). Once a reliable model is established, it is also effective for guiding design, since a reduction in PFIG is guaranteed to reduce the average noise and vibration levels within a building. Power flow analysis, in general, provides greater insight than one based on vibration amplitude, for example, by enabling the dominant vibration transmission paths to be established (Talbot and Hunt, 2003b; Heaton and Talbot, 2015) (see Figure 2). Such energy-based methods are expected to be invaluable in developing future approaches to base-isolation design.

\section{Conclusions}

Base isolation of buildings is well established as one of the most effective techniques for limiting the disturbance caused by groundborne vibration. Despite this, the lack of guidance on all aspects of design is a matter of significant concern for practicing engineers, with current designs being developed using a combination of prior experience, site vibration measurements, limited theoretical modelling and engineering judgement. There is a real need for an efficient, evidence-based design approach, based on robust engineering science that acknowledges the levels of uncertainty and specific practical constraints encountered in practice. 

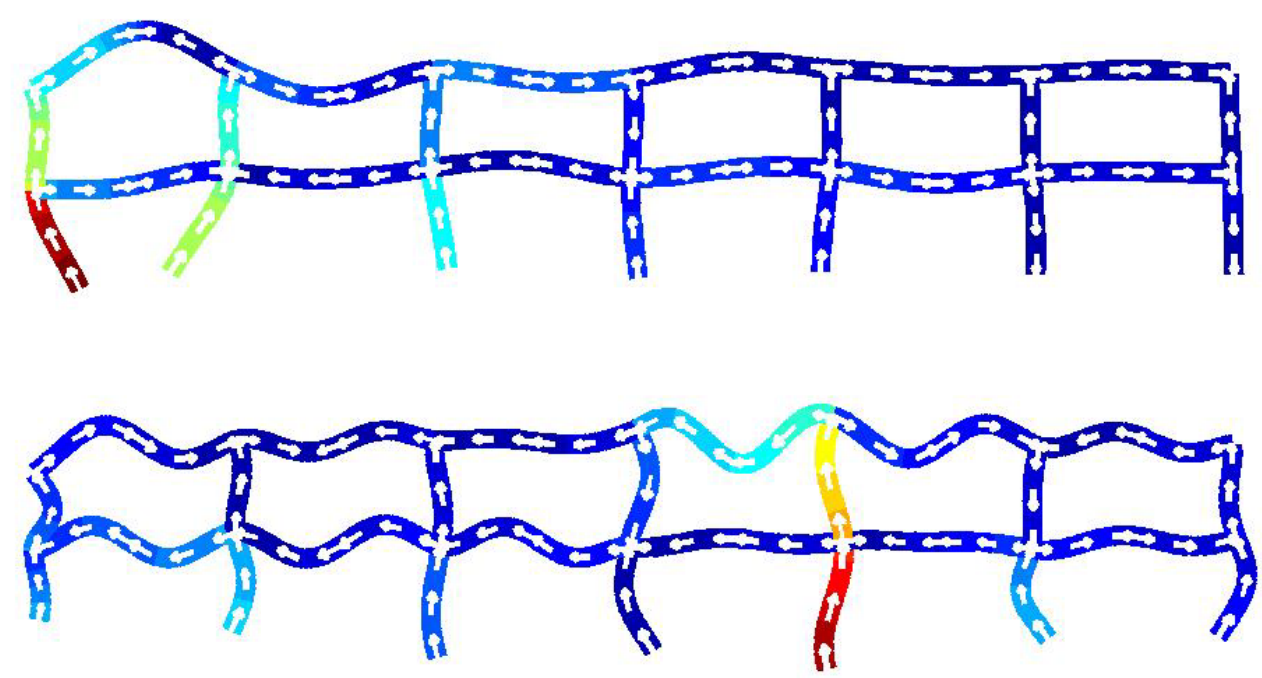

Figure 2. An example application of power flow analysis to investigate partial base-isolation. The dominant vibration transmission paths within a portal-framed building model, excited by surface Rayleigh waves, are seen to change with frequency: top, $25 \mathrm{~Hz}$; bottom, $100 \mathrm{~Hz}$.

Just as a performance-based design approach is leading to structures of predictable seismic performance, so too, it is hoped, will a similar approach lead to buildings with predictable isolation performance against groundborne vibration. Achieving this requires a concerted effort to address a number of challenges, in particular, to:

- consolidate previous research and practical experience, with a view to establishing universal agreement on serviceability limits for both perceptible vibration and re-radiated noise in buildings;

- develop generic, design evaluation methods that are versatile, robust and efficient, which account for essential dynamic behaviour, such as soil-structure interaction, and, wherever possible, make effective use of site vibration measurements to support modelling and reduce uncertainty;

- introduce a new probabilistic approach to design evaluation, to quantify the inherent uncertainties associated with, not just the physical system, but also human response.

By systematically addressing the above challenges, by developing models and taking advantage of measurement opportunities whenever they arise, researchers and practicing engineers may together develop the required procedures and guidelines. Significant research and development remains but work is in progress. 


\section{References}

Association of Noise Consultants (2012) ANC Guidelines: Measurement \& Assessment of Groundborne Noise and Vibration, $2^{\text {nd }}$ edn. ANC, St Albans, UK.

Becker R and Foliente G (2005) PBB International State of the Art, EC $5^{\text {th }}$ Framework Performance Based Building Thematic Network 2001-2005, Final Report, CIBdf (PeBBU), Rotterdam.

Boxoen T, Risbey D and Weber C (2010) Train induced vibration isolation of the skyvue, Sydney Austraila. Proceedings of the $20^{\text {th }}$ International Congress on Acoustics, Sydney, Australia.

BS 6177 (1982). Guide to selection and use of elastomeric bearings for vibration isolation of buildings. BSI, London, UK.

BS 6472-1 (2008). Guide to evaluation of human exposure to vibration in buildings - Part 1: Vibration sources other than blasting. BSI, London, UK.

Commins DE, Leneutre C and Vanpeperstraete S (1990) Vibration isolation of trains in a French arts complex. Proceedings of the Institute of Acoustics 12: 31-38.

Coulier P, Lombaert G, and Degrande G (2014) The influence of source-receiver interaction on the numerical prediction of railway induced vibrations. Journal of Sound and Vibration 333: 2520-2538.

Devin A, Fanning PJ and Pavic A (2015) Modelling effect of non-structural partitions on floor modal properties. Engineering Structures 91: 58-69.

DIN 4150-2 (1999) Structural vibration - Part 2: Human exposure to vibration in buildings. Deutsches Institut für Normung, Berlin, Germany.

Elias P and Villot M (2012) Review of existing standards, regulations and guidelines, as well as laboratory and field studies concerning human exposure to vibration. RIVAS EU project report rivas-wp1-d1-4-v03.

Fiala P, Degrande G and Augusztinovicz F (2007), Numerical modelling of ground-borne noise and vibration in buildings due to surface rail traffic. Journal of Sound and Vibration 301: 718-738.

Francois S, Schevenels M, Lombaert G and Degrande G (2014) Numerical modeling and in situ vibration measurements during the design and construction of low vibration floors at the Corelab 1B research facility. Proceedings of ISMA 2014, International Conference on Noise and Vibration Engineering, Leuven, Belgium.

Ghobarah A (2001) Performance-based design in earthquake engineering: state of development. Engineering Structures 23: 878-884.

Gordon CG (1991) Generic criteria for vibration-sensitive equipment. Proceedings of the SPIE Conference on Vibration Control and Metrology 1619: 71-85, San Jose, USA.

Griffin MJ (1990) Handbook of Human Vibration. Academic Press.

Grootenhuis P (1990) Structural Elastomeric Bearings and Resilient Seatings. In Polymers and Polymer Composites in Construction, Hollaway I (ed.). Thomas Telford, London, UK.

Gupta S, Stanus Y, Lombaert G and Degrande G (2009a) Influence of tunnel and soil parameters on vibrations from underground railways. Journal of Sound and Vibration 327: 70-91.

Gupta S, Degrande G and Lombaert G (2009b) Experimental validation of a numerical model for subway induced vibrations. Journal of Sound and Vibration 321: 786-812.

Hanson CE, Towers DA and Meister LD (2006) Transit Noise and Vibration Impact Assessment, Report FTA-VA90-1003-06, U.S. Department of Transportation, Federal Transit Administration, Office of Planning and Environment.

Heaton MJ and Talbot JP (2015) A power-flow based investigation into the performance of partial base-isolation for mitigating groundborne noise and vibration in buildings. Proceedings of the $22^{\text {nd }}$ International Congress on Sound and Vibration, Florence, Italy.

Henson P and Charles JG (2000) Vibration isolation of the IMAX Cinema, Waterloo, London. Proceedings of the Institute of Acoustics 22(2), pp. 255-262. 
Henson P (2009) The isolation from railway vibration of the BBC Egton Wing, Portland Place, London. Proceedings of Euronoise 2009, Edinburgh, Scotland.

Hunt HEM (1996) Modelling of rail vehicles and track for calculation of ground-vibration transmission into buildings. Journal of Sound and Vibration 193(1): 185-194.

Hussein MFM, Hunt HEM, Kuo KA, Costa PA and Barbosa J (2013) The use of sub-modelling technique to calculate vibration in buildings from underground railways. Proceedings of the Institution of Mechanical Engineers Part F: Journal of Rail and Rapid Transit 0(0): 1-12.

ISO 2631-2 (2003). Mechanical vibration and shock - Evaluation of human exposure to whole-body vibration Part 2: Vibration in buildings $(1 \mathrm{~Hz}$ to $80 \mathrm{~Hz})$. International Standards Organisation.

Jones S, Kuo KA, Hussein MFM and Hunt HEM (2012) Prediction uncertainties and inaccuracies resulting from common assumptions in modelling vibration from underground railways, Proceedings of the Institution of Mechanical Engineers Part F: Journal of Rail and Rapid Transit 226(5): 501-512.

Lopes P, Costa PA, Ferraz M, Calcada R, and Cardoso AS (2014) Numerical modelling of vibrations induced by railway traffic in tunnels: from the source to the nearby buildings. Soil Dynamics and Earthquake Engineering 6162: 269-285.

Moss P (1982) Resilient mounting of structures on difficult sites. Noise \& Vibration Control Worldwide 13(7): 288291.

Naeim F and Kelly JM (1999) Design of Seismic Isolated Structures: From Theory to Practice. Wiley.

Newland DE (1993) An Introduction to Random Vibrations, Spectral and Wavelet Analysis, $3^{\text {rd }}$ edn. Longman, Harlow, UK.

Smith AL, Hicks SJ and Devine PJ (2009) Design of Floors for Vibration: A New Approach, SCI Publication P354. The Steel Construction Institute, Ascot, UK.

Talbot JP and Hunt HEM (2000) On the performance of base-isolated buildings, Building Acoustics 7(3): 163178.

Talbot JP and Hunt HEM (2003a) Isolation of buildings from rail-tunnel vibration: a review. Building Acoustics 10(4): 177-192.

Talbot JP and Hunt HEM (2003b) The effect of side-restraint bearings on the performance of base-isolated buildings, Proceedings of the Institution of Mechanical Engineers Part C: Journal of Mechanical Engineering Science 217: 849-859.

Talbot JP (2007) Base Isolation of Buildings for Control of Ground-borne Vibration. In Handbook of Noise and Vibration Control, (Crocker MJ (ed.)). Wiley.

Talbot JP, Hamad WI and Hunt HEM (2014) Base Isolated Buildings and the Added-Mass Effect. Proceedings of ISMA 2014, International Conference on Noise and Vibration Engineering, Leuven, Belgium.

Transport for London (2012) Noise and Vibration Asset Design Guidance, LUL Document Reference: G1323.

Waller RA (1969) Building on Springs. Pergamon Press.

Willford MR and Young P (2006) A Design Guide for Footfall Induced Vibration of Structures. The Concrete Society, Camberley, UK. 